\title{
ENTRE VÍCIOS E VIRTUDES: A SÁTIRA DOS GOLIARDOS MEDIEVAIS (SÉCULOS XI-XIII)
}

\section{ENTRE VICIOS Y VIRTUD: LA SATIRA DE LOS GOLIARDOS MEDIEVALES (SIGLOS XI-XIII)}

Helena Macedo Ribas ${ }^{1}$

Resumo: Durante o período conhecido como Idade Média, existiram diversas manifestações culturais que eram dinâmicas e circulavam entre as regiões de maior trânsito de pessoas, como as cidades. Essas manifestações tinham "públicos" mais ou menos específicos, como os trovadores que se apresentavam nas cortes nobiliárquicas, ou os jograis que eram mais comuns nas feiras, e isso determinava, entre outras coisas, as temáticas das canções. Temos outro segmento, pouco estudado, que são os goliardos, estudantes das universidades que escreviam em latim, para outros estudantes e doutos. O presente artigo visa explorar aspectos da poesia goliárdica medieval, com o objetivo de traçar algumas características da vida errante dos poetas goliardos, e de que forma esse modo de vida é representado em sua poesia.

Palavras Chave: poesia medieval; goliardos; Carmina Burana.

Resúmen: A lo largo de lo periodo conocido como Edad Media, existieron diversas manifestaciones culturales que eran dinámicas y circulaban por entre las regiones de mayor tránsito de personas, como las ciudades. Esas manifestaciones tuvieron "publicos" más o menos específicos, como los trobadores que se presentarban em las cortes de nobles, o los jograles que eran comunes em las férias, y eso determinaba, entre otras cosas, los temas de las canciones. Tenemos um otro segmento, poco estudiado, que son los goliardos, estudiantes de las universidades que escribieron em latín, para otros estudiantes. Lo presente artículo preten-

${ }^{1}$ Graduanda do sétimo período do curso de História - licenciatura e bacharelado, orientada pela professora Dra. Fátima Regina Fernandes.

Lattes: http://lattes.cnpq.br/6293826197956957. 
de explorar aspectos de la poesia goliárdica medieval, com lo objectivo de hallar algunas características de la vida errante de los poetas goliardos, y de que manera ese modo de vida es representado em su poesia.

Palabras-Llave: poesía medieval; goliardos; Carmina Burana.

\section{Introdução}

O século XII foi um século de intensas transformações nas sociedades medievais ocidentais, no qual existem vários movimentos ocorrendo concomitantemente, como o crescimento das atividades comerciais, a gradual centralização do poder régio nos diversos reinos e o movimento cruzadistico; uma proposta renovada de espiritualidade representada pela ordem de Císter, que propunha uma religiosidade voltada ao trabalho, mais simples e otimista com relação a ordem de Cluny; Há também um grande movimento de heresia, com os cátaros e os valdenses que a igreja precisou combater. Nesse cenário, ainda temos o que ficou conhecido como "renascimento do século XII" graças ao surgimento das universidades e um resgate de pensadores gregos, especialmente Aristóteles. É precisamente sobre a influência das universidades nessa sociedade sobre alguns segmentos da população que surgem os poetas tema deste artigo, os Goliardos.

A palavra Goliardo pode ter dois significados possíveis: o primeiro, ligado ao pecado da Gula, visto que os homens que eram identificados assim eram amantes em particular do vinho e da boa mesa; outro significado os liga ao gigante bíblico Golias, que foi derrotado por Davi no Antigo testamento, por confiar demais em suas técnicas e armamento, além de seu porte físico, enquanto Davi confiava em Deus. Villena 
aponta que esse significado pode ter sido dado por Bernardo de Claraval, numa carta que escreve contra o seu rival Abelardo (endereçada ao papa Inocêncio III, na qual chama Abelardo de Golias) este considerado pelo autor um goliardo na sua juventude. (VILLENA, 2010: 47)

Em resumo, os goliardos são clérigos vagantes. São estudantes, que podem ou não pertencer ao clero, mas que em sua maioria ao menos possuía a tonsura. Habitavam o ambiente universitário, e transitavam entre as cidades que contavam com universidades, como Paris ou Tréveris, em busca dos mestres que oferecessem a disciplinas que mais thes agradassem. Segundo Mariateresa Brocchieri, havia uma categoria de trabalho que podemos considerar como o trabalho intelectual, apesar desta não ser uma palavra medieval. Eram homens que se dedicavam as letras e ao ensino, e eram conhecidos como "doutos", "professores" e “clérigos”. É interessante pontuar que há uma laicização da palavra clérigo nos séculos XI e XII, uma vez que era esperado que todo membro da igreja fosse letrado, os letrados eram identificados como membros da igreja. Mais tarde, qualquer membro de uma escola, não importando o seu nível, era considerado clérigo (BROCCHIERI, 1987: 194-195). Essa disseminação das escolas vem de encontro com um reavivamento das cidades, no mesmo período, de forma que quando as cidades ainda não eram pontos de grande circulação de pessoas, as catedrais e abadias detinham o ensino. Com o crescimento das cidades, surgem as universidades vindas da necessidade de se construir um ensino mais organizado, como uma corporação de ofício, onde a função de "homem de letras" fosse reconhecida. (BROCCHIERI, 1987: 198-199) 
Os goliardos eram frequentadores assíduos das tabernas, o que teve um impacto considerável em sua poesia visto que uma parte do códice é dedicada às atividades tabernárias, como beber e jogar. $\mathrm{O}$ códice principal, conhecido por nós hoje como Carmina Burana, é datado do século XIII e foi encontrado no século XIX num mosteiro de São Benedito na região da Baviera, atual sul da Alemanha, e conta com 229 composições em latim e 47 em médio alto alemão, configurando-se assim o maior códice de canções não religiosas da Europa. Porém esse não é o único códice goliárdico de que temos notícia; existem ainda 3 outros: Carmina Arundeliana, datado do século XI e encontrado na região do sul da atual Inglaterra; Carmina Cantabrigensia também do século XI e também encontrado na Inglaterra, e por fim o Carmina Rivinpullensia, encontrado na atual Espanha e é datado do Século XIII.(SOLA, 2006: 912)

No códice principal, podemos notar uma divisão temática, que por muitas vezes os tradutores e filólogos mantém e /ou acentuam: a primeira parte, os poemas "morais", no qual estão poemas que condenam a conduta da igreja e de seus membros de altos cargos, especialmente contra a simonia e a corrupção e decadência moral dos mesmos; geralmente tem um tom satírico, mas algumas vezes são críticas duras e diretas a essas condutas. A segunda parte é a mais extensa do códice, e dá conta dos poemas amorosos, que trazem topos tipicamente medievais, como a primavera e a renovação da vida após o inverno, o "morrer de amor", entre outros; porém não devemos confundir com a lírica cortesã, que continha um código de comportamento implícito que envolvia 
principalmente a contenção dos desejos e o serviço vassálico à Dama, que geralmente era de um extrato social mais alto do que o trovador que lhe dirigia a homenagem. A lírica amorosa goliárdica era o oposto: a não contenção dos desejos e a inexistência de damas de alta linhagem em suas poesias, que eram substituídas por pastoras e camponesas (pastorelas) e que continham um traço de experiência pessoal, o que leva Villena a caracterizar a poesia goliárdica, não somente a amorosa, mas como um todo, como poesia de experiência (VILLENA, 2010: 66-76). Por fim, temos o extrato sobre o qual nos debruçaremos neste estudo, que dá conta das poesias lúdico-tabernárias e que tinham como temas o vinho, o jogo e a falta de preocupação com o amanhã, numa valorização das experiências terrenas. (SOLA, 2006: 13-25)

\section{Experiência goliárdica}

Nossa proposta é analisar aqui duas canções do Carmina Burana, classificadas como lúdico tabernárias. A primeira é atribuída ao Archipoeta da Colônia e se chama Estuans Intrinsecus Ira Vehementi e a segunda é anônima, intitulada Cum "In Orbem, Universum” decantatur: "Ite”. Essas canções traçam algumas características interessantes sobre ao modo de vida de um goliardo, e também sobre sua mentalidade. ${ }^{2}$

Em Estuans Intrinsecus Ira Vehementi, há a famosa "confissão" do Archipoeta de Colônia sobre os pecados. Nas primeiras estrofes o eu

${ }^{2}$ É necessário pontuar que a grande maioria das canções do códice são anônimas, mas que existem alguns goliardos célebres aos quais foram atribuídas canções, entre eles o Archipoeta, Hugo Primas e Gualtero (ou Walther) de Châtillon. 
lírico está perdido, sem rumo emocionalmente; se compara com uma folha ao vento no outono, que não sabe onde vai parar. O esforço de se preocupar com as questões da alma é muito maior do que o de jogar, e ele junto com os jovens vai pelo "caminho largo"3. O poema todo tem um tom de lamentação, mas ao mesmo tempo há o prazer de praticar esses pecados, como se ao relatar esses pecados ele se lembra do prazer que lhe proporcionou praticá-los, e perde um pouco o foco do pedido de perdão. As recorrências a Vênus, deusa do amor, que só concede o sofrimento para os corações fortes, mostram o quanto o eu lírico se vê necessitado da presença de mulheres, mesmo as que não pode ter, para seu conforto. Mas Vênus não é a única recorrência a mitologia: o eu lírico se põe na presença das divindades, como Baco (que pelo vinho se apodera de seus pensamentos) e Febo, que lhe agrada com histórias. Além disso, há a afirmação de que o eu lírico escreve seus melhores poemas após perder até as roupas no jogo, chegando a se colocar como melhor que o poeta romano Ovídio depois de beber um pouco. Já nas ultimas estrofes, o eu lírico volta a pedir perdão, a um príncipe e ao bispo de Colônia, e que este lhe dê a penitência justa por seus atos.

Primeiramente, devemos delimitar duas "categorias" de goliardos: a primeira, chamada por Villena de goliardos "das letras" são aqueles que apesar de comporem canções acerca dos temas goliárdicos mais comuns citados anteriormente, não levam uma vida vagante e preferem

\footnotetext{
${ }^{3}$ É uma referência a uma passagem do evangelho de Mateus, onde se lê que o caminho largo leva aos pecados e a perdição, enquanto o caminho estreito e mais difícil é o certo, pois ele leva a salvação.
} 


\section{Cadernos de Clio, Curitiba, n. ${ }^{\circ}$ 5, 2014}

se estabelecer. É o caso de Gualtero de Chatillon, que foi professor em Chatillon durante boa parte de sua vida e que é responsável por alguns poemas dos mais veementemente críticos, como a canção Propter Sion non Tacebo, que enumera uma longa lista de desvios da igreja, compara cardeais a piratas que brigam por ouro e a própria Igreja com monstros lendários que sorvem tudo a sua volta, citando inclusive um homem chamado Francón, que foi tesoureiro do Papa em seu tempo e o acusa de acabar com o mundo, como um redemoinho.

A segunda categoria de goliardo é o goliardo "por excelência", pois este é conhecedor das formas de escrever poesia, é douto, mas ainda assim é vagante. É o caso do Archipoeta, que era protegido de Rainaldo de Dassel, arcebispo de Colônia, e este por sua vez era homem de confiança de Frederico I, imperador do Sacro Império Romano Germânico. Na companhia de Rainaldo, o Archipoeta percorreu diversas cidades, como Pavia, Navarra, Salerno e Viena, nas campanhas do imperador, e este arcebispo proveu o sustento do poeta por muitos anos, até que em uma dessas incursões Archipoeta adoece e definha no mosteiro de São Martim. Podemos afirmar que o Archipoeta é um goliardo por excelência, pois provavelmente sabia do fim que lhe aguardava, mas nem por isso deixou de viver a vida como melhor lhe parecia, cercado de vinho, jogo e mulheres. (VILLENA, 2010: 77-85)

Nesta canção fica implícito o tom de sátira em algumas estrofes, mas em outros ele é bem evidente, como na estrofe 12:

Es mi intención morir en la taberna, 
Para que de la boca del moribundo el vino esté cerca;

Entonces cantarán los coros de los ángeles con más fiesta:

"Dios a este bebedor proteja" (SOLA, 2006: 222)

Onde há uma operação de inversão de valores, no qual o ato de beber é louvável e redime o pecador tanto quanto uma oração, pois os anjos o receberão com festa. Esta estrofe é um bom exemplo da sátira goliárdica, que consiste em inverter o sistema de valores da época, e transformar os pecados em virtudes, como nesse caso, onde beber descomedidamente é um caminho para a salvação enquanto a sociedade exige exatamente o oposto. Segundo Villena, este poema "no es um pliego de desculpas, sino la autoconfesión, casi pragmática, de um rebelde, com algunas líneas de cruces y moralidad prestada" (VILLENA, 2010: 83)

Devemos lembrar que o sistema de valores medieval é impregnado pelo cristianismo, pelas lições da Bíblia. Durante os séculos XI e XII há uma transformação nesses valores, que é fundamental para entendermos as outras transformações desse período. Segundo Jacques Le Goff, até o século XI predominava uma visão pessimista do homem sobre si mesmo: o homem, representado por Adão, criatura divina, foi feito o senhor da natureza durante a Criação; mas a mulher, Eva, é enganada pela serpente, pelo Mal, e ambos são obrigados a deixar o paraíso, e a viver em sofrimento (através do trabalho manual para o homem e pelo parto para a mulher) em vergonha (da nudez, do pecado) e por fim, serem arrebatados pela Morte; porque o sofrimento tem dois significados: a penitência pelo pecado original, e como instrumento de salvação. 
Nos séculos XI e XII, esse conceito de sofrimento como meio de salvação ganha força, e toma forma a ideia de que o homem que sofre se assemelha a Jesus no momento de sua paixão: apesar de todos os sofrimentos, Jesus ainda é divino; então o homem se aproxima da ideia de que ainda é uma criação de Deus, e foi feito a sua imagem e semelhança, tornando-se mais otimista. Logo, a inversão goliárdica de valores é a operação de colocar os vícios no lugar dos valores, e a diversão no lugar do sofrimento. (LE GOFF, 1987: 14-17)

O segundo poema que analisaremos, Cum "im Orbem Universum” decantatur: "Ite”, é uma canção que lista as características e o que é necessário para ser um goliardo, numa espécie de constituição que coloca os clérigos vagantes como uma ordem monástica. Não são permitidos avarentos, nem orações de madrugada, e os pobres sempre tem auxilio. São bem vindos todos os homens, ricos e pobres, de todos os lugares, como notamos na estrofe 3:

"A bávaros, sajones, a los de Austria y a los de Marca,
cuantos sois, a vosotros os pido, nobles camaradas
escuchad con atención las nuevas ordenanzas:
que se mueran los avaros y los de condición tacaña" (SOLA,
2006: 247)

Essa estrofe mostra uma coisa muito importante: o alcance do "movimento" goliárdico, pois quando o poema se coloca como uma espécie de constituição de ordem se dirige a todos os goliardos espalhados pelo mundo, e cita os principais lugares onde o movimento ocorre: o sul da Alemanha, a Inglaterra, a Áustria (particularmente Viena). Pode- 
mos supor que esta poesia é de um período onde o movimento está no auge, espalhado por várias localidades e ocorrendo concomitantemente, pois Villena nos diz que é provável que os clérigos vagantes tenham surgido primeiramente no norte de França, principalmente em Paris, e deste ponto irradiado para outras regiões da Europa.

Outra coisa a ser notada nesta canção é a proximidade do tema com os temas das canções morais, a aversão a avareza e a proibição expressa das orações de madrugada, as "maitires", pois a mente não está acordada nesta hora e pode haver visões estranhas; isso mostra que os temas em si não são estanques desta ou daquela classificação, eles aparecem como parte de um "arsenal” de temáticas goliárdicas. Porém, essa canção continua sendo uma sátira muito bem articulada: além da inversão de valores apontada anteriormente (por exemplo, no lugar das orações de madrugada, se fartar de vinho já pela manhã) o próprio fato da canção ser uma constituição de uma ordem fictícia é uma sátira sobre as ordens existentes, ao colocar os goliardos como uma ordem institucionalizada.

Já nas ultimas estrofes a questão de ajudar os pobres é retomada, colocando a "ordem" a serviço dos mais necessitados, pois com eles a única fortuna é a que vem através do jogo. A palavra "fortuna" aqui pode ter duplo significado: o dinheiro ganho na mesa de jogo e a própria sorte, que pode sorrir ao pobre nos momentos mais difíceis. A "ordem" dos goliardos aceita a todos: os justos e os injustos, os altos, os baixos, os estudantes e seus mestres, monges que perderam a tonsura, todos os desajustados são bem vindos, bem como os bem colocados socialmente. 
Além de todos esses postulados, há o da vestimenta, onde quem sair da localidade onde se encontra a ordem, somente pode vestir uma peça de roupa: se usar túnica tem de deixar a capa; se usar calças deve deixar as meias e assim por diante.

Os dois poemas têm em comum o grande teor satírico, mais implícito no Archipoeta, mas explícito no acima analisado. Apesar de ter algumas especificidades que devem ser levadas em consideração, a sátira goliárdica não foge muito da sátira medieval, que está estritamente ligada com a cultura popular. ${ }^{4}$ Segundo Mikail Bakhtin, as paródias dos textos sagrados eram uma literatura corrente e bastante difundida na Idade Média, demonstrando um caráter universal do riso, que busca parodiar o extrato superior da sociedade e também uma liberdade, relativa por estar confinada somente aos dias de festa, como o carnaval, mas plena em oposição à postura de jejum e ascetismo que predominavam no restante do ano, por isso as comemorações eram sempre regadas a muita comida e bebida. Outra característica do riso medieval é sua relação com uma verdade popular não oficial, pois a sociedade convivia com o medo que a Igreja e o poder secular imprimiam nas pessoas e o riso representava uma vitória sobre esse medo. Apesar dessas esferas do cômico medieval, não havia uma posição deliberada de protesto contra esse sistema, pelo contrário, o homem que escreve as paródias geralmente é devotado à sua fé e vê no riso um "fim didático e edificante"

\footnotetext{
${ }^{4}$ Vale ressaltar que os goliardos se aproveitam desses mecanismos populares, mas os temas possuem variações importantes, que já foram destacadas.
} 
convivendo com essas duas esferas, que não se misturam. (BAKHTIN, 1987: p. 80-82)

Ao parodiar os ritos sagrados e as liturgias, os goliardos seguem uma tradição popular que era vista com bons olhos pela Igreja, pois era uma forma de diversão que não denegria os seus membros e nem subvertia os dogmas. Porém, os poemas satíricos goliárdicos continham um teor de crítica ao posicionamento da Igreja em algumas questões, como por exemplo, a simonia. Quando as poesias goliárdicas falam de simonia, são duras e extremamente questionadoras, onde a crítica é feita diretamente aos dirigentes da Igreja. Essa crítica pode vir de forma cômica, o que acontecia uma grande parte das vezes, mas às vezes as canções somente traziam a crítica esmagadora às posturas da igreja. No poema Cum “in orbem..." a crítica à igreja vem na forma satírica, ao "institucionalizar" a ordem dos goliardos e não permitir que o dinheiro das pessoas seja um fator determinante para o aceite delas ou não na ordem, e onde os pobres têm sempre abrigo e não são necessárias orações de madrugada, colocando a questão do dinheiro como um fator importante para a Igreja, já que a ideia da canção é propor práticas contrárias às realizadas por esta instituição.

\section{Recepções da poesia goliárdica}

Quando pensamos na recepção da poesia goliárdica, devemos ter em mente dois aspectos: a recepção do público alvo e a recepção do sujeito satirizado, neste caso a Igreja. Como sabemos, as canções goliárdicas são feitas em latim, diferentemente dos outros gêneros poéticos 
de sua época, que utilizavam as línguas romance. Analisemos o que nos traz Paul Zumthor sobre os goliardos:

Os goliardos giróvagos, rompendo com a escola ou com a abadia, fizeram profissão de jocosos, poetas e, especialmente, cantores, a esse título misturados na multidão dos "jograis" leigos, embora várias obras atribuídas a eles, como os Carmina Burana, provavelmente só tenha agradado a públicos muito limitados. (ZUMTHOR, 1993: 57-58)

Podemos supor que os goliardos tiveram algum alcance entre $o$ povo mais comum, que cantaram suas canções nas feiras e nas festas, e que sua poesia foi essencialmente oral, antes de ser cristalizada no códice do século XIII, mas que por causa da língua e também das temáticas, cheias de referências a Bíblia, a filosofia grega e ao seu panteão, poucos poderiam realmente entender do que se tratava; somente aqueles que fossem letrados, versados no latim e que tivessem estudado mais ou menos da mesma forma como o goliardo estudou é que poderia entender as referências. Além dessa questão, a poesia goliárdica é o que Villena chama de "poesia de experiência", pois as poesias narram experiências, e é bem possível que sejam as experiências dos próprios clérigos vagantes, tanto no campo amoroso, quanto no satírico. Então é bem possível que essas canções fossem muito disseminadas entre os estudantes que tinham contato com esses outros estudantes vagantes, tanto que temos registro da existência dessas canções por pelo menos dois séculos (XI$\mathrm{XII}$ ), que sobreviveram tempo suficiente para comporem códices. (VILLENA, 2010: 66-69) 
Quanto à recepção da Igreja, num primeiro momento a poesia goliárdica era vista como mais uma poesia satírica, como explicado acima. Mas a partir do século XIII há uma hostilidade com os goliardos, quando o movimento já perdia força e propósito. Segundo Villena, há registros de três documentos oficiais condenando os clérigos vagantes: a primeira condenação foi no concílio de Tréveris, em 1227, que proibia os goliardos de participarem do ofício divino. A segunda foi no concílio de Rouen, em 1231, no qual os goliardos poderiam perder os direitos eclesiásticos e a tonsura. No sínodo de Cahors em 1289, quando o movimento já tinha se descaracterizado, goliardos e jograis são condenados por suas atividades, mas neste momento muito do que já foi o movimento goliárdico se perdera. Além dessas condenações, temos outra de Afonso $\mathrm{X}$, rei de Castela, proibindo os clérigos de serem vagantes, na primeira das Siete Partidas e uma do papa Bonifácio VIII, condenandoos universalmente a perderem todos os direitos, se algum clérigo não levasse seu ministério a sério e "agisse como um goliardo" (VILLENA, 2010: 153-154).

Através dessas condenações, podemos concluir que apesar de existirem barreiras entre os goliardos e o "popular", havia uma disseminação de suas canções a ponto de ser necessária uma intervenção da igreja para que essas canções fossem suprimidas, e de que as críticas "incomodaram" de alguma forma, visto que depois de dois concílios e um sínodo regionais, há uma condenação por parte do Papa e universal, e também uma condenação régia. Além das críticas, a própria figura do goliardo representava um desvio moral: sem casa, vivendo nas tabernas 
com a ajuda de terceiros e cometendo os excessos que a sociedade desaprovava, os goliardos acabaram de certa forma, marginalizados por viver ao revés do sistema de valores vigente.

\section{Conclusão}

Através dos dois emblemáticos poemas analisados neste artigo, podemos notar uma série de características dos clérigos vagantes através de suas poesias, com relação ao seu estilo de vida e sua percepção da sociedade. Percebemos também que algumas questões que ganharam espaço depois deles, como o auxílio aos mais pobres, já eram uma preocupação que existia, em maior ou menor grau em sua época, e que era uma coisa cobrada das autoridades eclesiásticas, de tal forma que no fim do século XII e início do XIII surge uma das maiores ordens religiosas da Idade Média: os franciscanos, que tinha em seu cerne o voto de pobreza e o auxílio aos mais necessitados. Por essa e outras razões não é exagero supor que a poesia goliárdica é sintomática das tensões sociais do século XII, das transformações que ganharam corpo depois deles, pois ligados ao ambiente universitário, citadino, ao vagar de cidade em cidade e observar, experimentar outras realidades, pouco distintas da sua talvez, mas que impactam em sua poesia de diversas formas.

\section{Bibliografia}

BAKHTIN, M. A cultura popular na Idade Media e no Renascimento: o contexto de François Rabelais. São Paulo: Hucitec, 2010. 
BROCCHIERI, F. B. El intelectual. IN: LE GOFF, J. El hombre medieval. Madrid: Alianza editorial, 1987.

LE GOFF, J.El hombre medieval. IN: El hombre medieval. Madrid: Alianza editorial, 1987.

MACEDO, J. R. Riso, cultura e sociedade na Idade Média. Porto Alegre/São Paulo: Ed. Universidade/ EDUSP, 2000.

MALEVAL, M. A. T. Poesia medieval no Brasil. Rio de Janeiro: Ágora da Ilha, 2002.

RIQUER, M., VALVERDE, J. M. Historia de la literatura universal. Barcelona: Editorial Noguer, 1957. Tomo I.

SOLA, J. E. (Edição, tradução e seleção). Carmina Burana: Antologia. Madrid: El Libro Del Bolsillo, Alianza Editorial, 2006.

SPINA, S. A lírica trovadoresca. São Paulo: EDUSP, 1996.

. A cultura literária medieval: uma introdução. São Caetano do Sul: Ateliê Editorial, 1997.

VILLENA, L. A. de. Dados, amor y clérigos: El mundo de los goliardos em la Edad Media europea. Sevilla: Renascimiento, 2010.

ZUMTHOR, P. A letra e a voz: a "literatura" medieval. São Paulo: Companhia das Letras, 1993. 